\title{
Embryonically Expressed GABA and Glutamate Drive Electrical Activity Regulating Neurotransmitter Specification
}

\author{
Cory M. Root, Norma A. Velázquez-Ulloa, Gabriela C. Monsalve, Elena Minakova, and Nicholas C. Spitzer \\ Neurobiology Section, Division of Biological Sciences and Center for Molecular Genetics, Kavli Institute for Brain and Mind, University of California, San \\ Diego, La Jolla, California 92093-0357
}

\begin{abstract}
Neurotransmitter signaling in the mature nervous system is well understood, but the functions of transmitters in the immature nervous system are less clear. Although transmitters released during embryogenesis regulate neuronal proliferation and migration, little is known about their role in regulating early neuronal differentiation. Here, we show that GABA and glutamate drive calcium-dependent embryonic electrical activity that regulates transmitter specification. The number of neurons expressing different transmitters changes when GABA or glutamate signaling is blocked chronically, either using morpholinos to knock down transmitter-synthetic enzymes or applying pharmacological receptor antagonists during a sensitive period of development. We find that calcium spikes are triggered by metabotropic GABA and glutamate receptors, which engage protein kinases A and C. The results reveal a novel role for embryonically expressed neurotransmitters.
\end{abstract}

Key words: GABA; glutamate; metabotropic receptors; calcium spikes; sensitive period; transmitter specification

\section{Introduction}

Assembly of the nervous system is a complex biological process that involves three distinct but overlapping stages of proliferation, migration, and differentiation. These phases of development determine much of its basic structure and function by producing the appropriate numbers of neurons, moving them into the correct positions, and endowing them with the machinery to establish proper connections and neuronal circuits underlying behavior. The generative roles of these early aspects of development have contributed to the interest in understanding the mechanisms involved.

Differentiation of the nervous system is achieved by a partnership between selective gene expression, gradients of signaling molecules, and electrical activity-driven mechanisms. Dependence on electrical activity used to be viewed as reliance on sodium-dependent action potentials with susceptibility to tetrodotoxin, which can appear late in development. It is now recognized to include other voltage-dependent channels, ligandactivated channels, and transient receptor potential (TRP) channels discovered more recently. In addition, many structural and functional components used in the mature nervous system have been discovered to have different functions during its construction. Mechanoreceptors and transmitter transporters acting in reverse generate electrical signals that can play roles in neuro-

\footnotetext{
Received 0ct. 27, 2007; revised Feb. 21, 2008; accepted March 26, 2008.

This work was supported by a grant from the National Institutes of Health to N.C.S. N.A.V.-U. was supported by Consejo Nacional de Ciencia y Tecnologia-University of California Institute for Mexico and the United States. We thank Marla Feller, Anirvan Ghosh, and Kurt Marek for comments on this manuscript and I-Teh Hsieh for technica support.

Correspondence should be addressed to Nicholas C. Spitzer at the above address. E-mail: nspitzer@ucsd.edu. DOI:10.1523/JNEUROSCI.4873-07.2008

Copyright $\odot 2008$ Society for Neuroscience $\quad 0270-6474 / 08 / 284777-08 \$ 15.00 / 0$
}

nal development. Thus, activity is now recognized to exist in multiple forms, many of which are present early in embryogenesis (Spitzer, 2006).

Neurotransmitters are expressed at early stages of development, long before synapse formation (Lauder et al., 1986; Ma et al., 1992; Antal et al., 1994; Berki et al., 1995), and their release can stimulate elevations of intracellular calcium (Blanton et al., 1990; Flint et al., 1999). They regulate proliferation in rat embryonic neocortical progenitor cells and subventricular zone neuroblasts, and zebrafish spinal interneurons (LoTurco et al., 1995; Liu et al., 2005; McDearmid et al., 2006). Embryonic transmitters also regulate the migration of cerebellar granule cells and neuronal precursors in the mouse postnatal subventricular zone (Komuro and Rakic, 1996; Yacubova and Komuro, 2002; Bolteus and Bordey, 2004). However, their roles in nervous system differentiation beyond proliferation and migration have been elusive (Spitzer, 2006). We therefore tested the hypothesis that embryonic transmitter signaling triggers machinery initiating activity-dependent differentiation.

We find that GABA and glutamate (Glu) are promiscuously expressed in the neural plate of developing Xenopus embryos. Suppressing synthesis of GABA or blocking GABA or glutamate receptors (GABARs or GluRs) causes an increase in the number of neurons expressing excitatory transmitters and a decrease in the number of neurons expressing inhibitory transmitters, which appear to be independent of cell proliferation or cell death. GABA and glutamate stimulate generation of calcium spikes that are an early form of excitability in these neurons, via metabotropic $\mathrm{GABA}_{\mathrm{B}}$ receptors and group III metabotropic GluRs (mGluRIIIs) that activate protein kinases A (PKA) and C (PKC). The role of this early electrical activity in transmitter specification is restricted to a brief period during which synapse formation takes place and swimming behavior begins. We propose a model in 
which the release of neurotransmitters at early stages of development has a function distinct from that associated with synaptic transmission, driving what was previously termed spontaneous activity that leads to gene expression necessary for appropriate transmitter specification. Maintaining the incidence of calcium spiking enables frequency-dependent control of the specification of different transmitters (Borodinsky et al., 2004).

\section{Materials and Methods}

Immunocytochemistry. Embryos and larvae were fixed in 4\% paraformaldehyde, with or without 0.025 to $0.1 \%$ glutaraldehyde, in PBS at pH 7.4, for $30 \mathrm{~min}$ to $2 \mathrm{~h}$ at $4^{\circ} \mathrm{C}$, incubated in sucrose for $2.5 \mathrm{~h}$, and embedded in OCT. Cryostat sections $10 \mu \mathrm{m}$ in thickness were made starting $400 \mu \mathrm{m}$ posterior to the back of the eyes over a region of $400 \mu \mathrm{m}$. Sections were incubated in a blocking solution of $2 \%$ goat serum, $1 \%$ fish gelatin, or $2 \%$ goat serum $/ 2 \%$ BSA for $0.5 \mathrm{~h}$ at $20^{\circ} \mathrm{C}$, followed by overnight or $3 \mathrm{~d}$ incubation with primary antibodies to glycine (Gly), GABA, choline acetyltransferase (ChAT), lim-3 (Millipore Bioscience Research Reagents, Temecula, CA), vesicular glutamate transporter 1 (VGluT1; Millipore Bioscience Research Reagents or Sigma-Aldrich, St. Louis, MO), glutamate, or human natural killer-1 (HNK-1) (Sigma-Aldrich) at $4^{\circ} \mathrm{C}$ and $2 \mathrm{~h}$ incubation with fluorescently tagged secondary antibodies at $20^{\circ} \mathrm{C}$. Triple stains were incubated at $4^{\circ} \mathrm{C}$ for $3 \mathrm{~d}$. Sections were mounted in Vectashield mounting medium with or without $4^{\prime}, 6^{\prime}$-diamidino-2phenylindole (DAPI; Vector Laboratories, Burlingame, CA) to track cell numbers. Labeling was examined on an Axioskop with $40 \times$ air or waterimmersion objectives and the appropriate excitation and emission filters for Alexa 350, Alexa 488, Alexa 594, and DAPI.

Morpholinos. Transcription-blocking morpholinos (MOs; GeneTools, Philomath, OR) were designed to the start sequences of $X$. laevis glutamic acid decarboxylase 65 (GAD65) and GAD67 genes. The GAD65 sequence was identified by PCR using primers from the $X$. tropicalis genome and GAD67 X. laevis sequence was taken from GenBank (accession number U38225). Respective morpholino sequences were AAAACCCCGAGCCAGGAGACGCCAT and GCAGGGTGTTCTCTTTCCTAAGCAT. Saline solution $(7-10 \mathrm{nl})$ containing $300 \mathrm{pg} / \mathrm{nl}$ of each morpholino and 30 $\mathrm{ng} / \mathrm{nl}$ fluorescent dextran tracer (10,000 molecular weight) were injected into both blastomeres at the two-cell stage. The control morpholino was CCTCTTACCTCAGTTACAATTTATA, a standard sequence from GeneTools that did not recognize any sequence in GenBank.

Pharmacology. Stock concentrations of drugs were 50 or $25 \mathrm{~mm}(R S)$ $\alpha$-methylserine-O-phosphate (MSOP), $50 \quad \mathrm{~mm} \quad(S)$ - $\alpha$-methyl-4carboxyphenylglycine (MCPG), $5 \mathrm{~mm} \mathrm{D}-(-)$-2-amino-5-phosphonopentanoic acid (D-AP5), $100 \mathrm{~mm}$ phaclofen (Tocris Bioscience, Ellisville, MO), $1 \mathrm{~mm}(-)$-bicuculline methobromide, $100 \mu \mathrm{M}$ GVIa $\omega$-conotoxin, $100 \mu \mathrm{M}$ flunarizine, $100 \mu \mathrm{g} / \mathrm{ml}$ tetrodotoxin, $10 \mathrm{~mm}$ veratridine, $1 \mu \mathrm{M}$ PMA, 1 M tetraethylammonium (TEA; Sigma-Aldrich), $1 \mu \mathrm{M}$ N6benzoyladenosine-3' ${ }^{\prime} 5^{\prime}$-cyclic monophosphate sodium salt (N6-benzoyl-cAMP; Axxora, San Diego, CA), $2 \mu \mathrm{M}$ calcicludine, and $1 \mu \mathrm{M}$ KT5720 $[(9 S, 10 S, 12 R)-2,3,9,10,11,12$-hexahydro-10-hydroxy-9-methyl-1-oxo9,12-epoxy- $1 H$-diindolo[1,2,3-fg:3', $2^{\prime}, 1^{\prime}$-kl]pyrrolo[3,4-I] [1,6]benzodiazocine-10-carboxylic acid hexyl ester; Calbiochem, San Diego, CA], dissolved in $2 \mathrm{~mm}$ calcium saline. 2,3-Dioxo-6-nitro-1,2,3,4tetrahydrobenzo[f] quinoxaline-7 sulfonamide (NBQX; $50 \mathrm{~mm}$; Tocris Bioscience) and $10 \mu \mathrm{M}$ bisindolylmaleimide (Sigma-Aldrich) were dissolved in DMSO. These stock solutions were diluted in saline $100 \times$ when acutely applied to preparations for calcium imaging and $10 \times$ when loading agarose beads. Fluorescently tagged $\omega$-conotoxin was purchased from Hans-Günther Knaus (Innsbruck Medical University, Innsbruck, Austria). To alter spike activity in vivo, an $80 \mu \mathrm{m}$ agarose bead (Bio-Rad, Hercules, CA) loaded with drugs or bovine serum albumin (control) was inserted between the neural tube and myotomes $\sim 400 \mu \mathrm{m}$ behind the eye primordium at $20 \mathrm{~h}$ of development (stage 18) and immunostaining was performed $2 \mathrm{~d}$ later (Borodinsky et al., 2004). Sections of beadimplanted embryos were collected anterior, through, and posterior to the bead.

Imaging. Neural tubes of stages 25-28 X. laevis embryos were dissected to expose the dorsal or ventral surface and loaded for 45-60 min with 5 $\mu \mathrm{M}$ Fluo-4 AM/0.01\% pluronic acid/1\% DMSO in $2 \mathrm{~mm}$ calcium saline. Images were acquired with Bio-Rad laser confocal systems at $0.2 \mathrm{~Hz}$ for periods of $30 \mathrm{~min}$ or $1 \mathrm{~h}$. The baseline incidence of calcium spiking was determined for the dorsal and ventral neural tube; values lying outside the normal distribution (incidence $>2$ SD from the mean; ventral, $21 \pm$ $7 \%$; dorsal, $15 \pm 7 \%$ ) were excluded from further consideration. Antagonists were then applied directly to the bathing solution and images were acquired for another $30 \mathrm{~min}$. In pharmacological rescue experiments, kinase agonists were applied $15 \mathrm{~min}$ after receptor antagonists. Movies were analyzed with Image J and NIH Image.

Statistics. Significance was assessed with Student's two-tailed $t$ test and values were considered different when $p<0.05$.

\section{Results \\ Neurotransmitters are promiscuously expressed at early stages}

To evaluate the extent of early expression of neurotransmitters in the spinal cord, we examined four transmitters during Xenopus embryonic development. At neural plate and early neural tube stages (stages 15 and 20), GABA and glutamate expression assayed by immunoreactivity (IR) to GABA (GABA-IR), glutamate (Glu-IR), and the vesicular glutamate transporter (VGluT1-IR) are observed in a large number of cells and often coexpressed (Fig. $1 A, E$ ). To investigate cell-type expression of these transmitters, we determined whether the presence of GABA and glutamate is consonant with that observed at later stages of development. Fully differentiated motoneurons (MNs) and RohonBeard sensory neurons (RBs) are identified by expression of molecular markers lim-3 and HNK-1 and are cholinergic and glutamatergic, respectively. Lim-3-IR is first detected at stage 14 (Taira et al., 1993) and HNK-1-IR is first detected at stage 20 (Nordlander, 1993). The numbers of neurons expressing these markers does not change significantly from the neural tube stage to the $3 \mathrm{~d}$ larva (stages $20-41$; HNK-1-IR, $14 \pm 2$ to $10 \pm 1$ neurons per $100 \mu \mathrm{m}$ of spinal cord; lim-3-IR, $21 \pm 1$ to $26 \pm 2$; $p>0.05)$. Fifty percent of HNK-1- and lim-3-expressing neurons are both GABA and Glu immunoreactive at early stages (Fig. $1 B-D)$. Glu-IR becomes restricted to RBs and GABA-IR to GABAergic (lim-3 and HNK-1 negative) interneurons by $3 \mathrm{~d}$ of development.

Because the developmental appearance of neurotransmitters in Xenopus is quite rapid, occurring within hours, the time resolution of our experiments does not reveal whether the appearance of GABA precedes the appearance of glutamate (Ben-Ari et al., 2007; Deng et al., 2007). However, both transmitters are expressed at the neural plate stage, preceding axon outgrowth and synapse formation. This question could be answered by live imaging of fluorescent reporter transgenes at a higher sampling rate, combined with immunostaining of transmitters, transmitter receptors, and molecular markers for different classes of interneurons.

Gly- and ChAT-immunoreactive neurons are first detected later in tailbud stage embryos (stages 25 and 30) (Roberts et al., 1988; Lopez et al., 2002), at which time they are appropriately expressed in glycinergic interneurons (lim-3 and HNK-1 negative) and lim-3-immunoreactive MNs (Fig. 1C,D,F). Neither neurogenesis nor cell death can account for differences in the number of immunoreactive neurons per section between stages (Hensey and Gautier, 1998; Schlosser et al., 2002). Thus, the initial expression of GABA and glutamate, but not ChAT and glycine, is promiscuous (Fig. $1 E$ ). The normal later pattern of transmitters in the spinal cord involves respecification of GABA and glutamate expression and de novo specification of acetylcholine and glycine expression (Fig. $1 F$ ). 

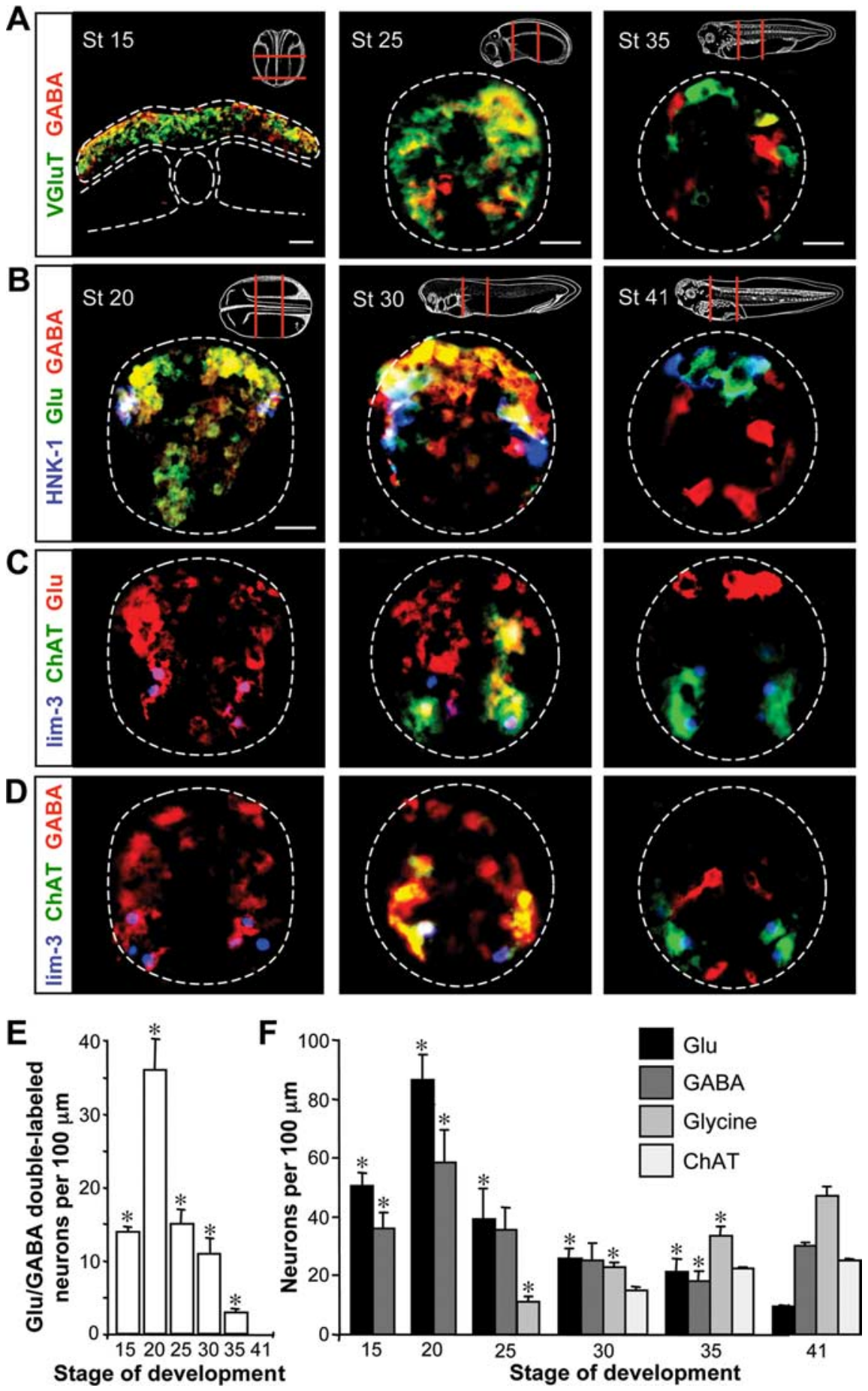

Figure 1. GABA and Glu are promiscuously expressed before synapse formation. $\boldsymbol{A}$, Immunostaining for GABA and VGluT1 demonstrates expression within neural tissue at the neural plate [stage (St) 15], early tailbud (St 25), and late tailbud (St 35) stages. Insets indicate regions from which sections were taken. White dashed lines identify the margins of the neural plate, notochord, somites, and neural tube. $\boldsymbol{B}$, Triple immunostaining reveals GABA and Glu in HNK-1-immunoreactive Rohon-Beard neurons at the early neural tube (St 20) and tailbud (St 30) stages that will become glutamatergic at 3 d of development (St 41). C, Triple staining for lim-3 with ChAT and glutamate shows transient expression of glutamate in motoneurons that later become cholinergic. $\boldsymbol{D}$, Triple staining for lim-3 with ChAT and GABA reveals transient expression of GABA in motoneurons. $\boldsymbol{E}$, Time course of the changes in glutamate/GABA coexpression during the development of the embryonic spinal cord. $\boldsymbol{F}$, Quantification of transmitter expression dynamics for Glu, GABA, glycine, and acetylcholine (assayed as ChAT immunoreactivity) per $100 \mu \mathrm{m}$ of spinal cord at different stages of development. Scale bars: $\boldsymbol{A}, \boldsymbol{B}, 20 \mu \mathrm{m} . n \geq 3$ embryos for $\boldsymbol{A}-\boldsymbol{F}$. $\boldsymbol{E}, \boldsymbol{F}$, Values are mean \pm SEM; asterisks indicate a significant difference from stage 41.

\section{GAD knockdown alters neurotransmitter expression}

The early transient expression of GABA and glutamate led us to test whether these neurotransmitters play a role in subse- quent transmitter specification in embryonic spinal neurons. We first injected MOs to knock down expression of GAD, the GABA synthetic enzyme. The effectiveness of MOs for $x G A D 67$ and $x G A D 65$ injected into both blastomeres at the two-cell stage was confirmed by reduction in the incidence of GABA-IR. Residual expression of GABA may be caused by differential knockdown of GAD translation resulting from inconsistent distribution of the morpholinos at subsequent cell divisions. When GAD is knocked down, the incidence of both GABA- and Gly-immunoreactive neurons is decreased in $3 \mathrm{~d}$ larvae. In contrast, the incidence of Glu- and ChATimmunoreactive neurons is increased (Fig. $2 A, C$ ). DAPI staining of nuclei indicates that the number of cells in the spinal cord does not differ between $G A D$ $\mathrm{MO}$, control MO, and control embryos both at the early tailbud stage and at $3 \mathrm{~d}$ larvae, suggesting that the changes in transmitter expression are not caused by cell proliferation or death (supplemental Fig. 1, available at www.jneurosci.org as supplemental material).

\section{GABA and glutamate receptor antagonists alter \\ neurotransmitter expression}

To test further the role of early transmitter signaling in subsequent transmitter expression, we implanted pharmacologically loaded agarose beads adjacent to the neural tube to block transmitter receptors chronically. This approach allowed us to restrict the perturbation to specific stages of development and to assay the role of early glutamate signaling as well as signaling by GABA. Beads were loaded with a combination of GABA receptor (GABAR) ionotropic (bicuculline) and metabotropic (phaclofen) antagonists, or a combination of GluR ionotropic (D-AP5, NBQX) and metabotropic (MSOP, group III, and MCPG, group I and II) antagonists. Beads were implanted at the time of neural tube closure and larvae were fixed at $3 \mathrm{~d}$ of age to examine transmitter expression. When beads are implanted with GABAR antagonists, the incidence of Glu- and ChAT-IR is increased and the incidence of GABA- and Gly-IR is decreased, mirroring the effect of GAD knockdown on transmitter specification. Strikingly, when beads are implanted with GluR antagonists, the incidence of Glu- and ChAT-IR is again increased and the incidence of GABA- and Gly-IR is decreased (Fig. $2 \mathrm{~B}, \mathrm{C}$ ). DAPI staining shows that the number of cells in the spinal cord does not change (supplemental Fig. 1, available at www.jneurosci.org as supplemental material) and implanting 
control beads loaded with bovine serum albumin has no effect on transmitter expression.

\section{GABA and glutamate regulate the} incidence of calcium spiking

To determine whether calcium spikes are driven by GABA and glutamate, we imaged spike activity on the dorsal and ventral surfaces of the neural tube at tailbud stages (stages 25-28) when activity is highest (Borodinsky et al., 2004), both in GAD MOinjected embryos as well as before and after acute application of transmitter receptor antagonists. In GAD MO-injected embryos, the incidence of calcium spike activity is reduced on both the dorsal and ventral surfaces (Fig. $3 A, B$ ) and frequency is reduced only ventrally (supplemental Fig. $2 A$, available at www.jneurosci.org as supplemental material). Injections of control MO have no effect on calcium spike incidence or frequency. Applying combinations of antagonists for GABA receptors (bicuculline and phaclofen) or glutamate receptors (D-AP5, NBQX, MSOP, and MCPG), we observed decreases in the incidence, but not frequency of calcium spikes, on the dorsal and ventral neural tube (Fig. 3A,C and supplemental Fig. 2B, available at www.jneurosci.org as supplemental material).

\section{GABA and glutamate act primarily via} $\mathrm{GABA}_{\mathrm{B}}$ and $\mathrm{mGluRIII}$ receptors

To assess the contributions of specific ionotropic and metabotropic receptors, we tested individual GABAR and GluR antagonists. On the dorsal surface, the incidence of calcium spikes is reduced in the presence of MSOP, phaclofen, and bicuculline and NBQX, implicating mGluRIII, $\mathrm{GABA}_{\mathrm{B}} \mathrm{R}, \mathrm{GABA}_{\mathrm{A}} \mathrm{R}$ and AMPA receptor (AMPAR). Ventrally, only MSOP and phaclofen reduce spike incidence, implicating mGluRIII and $\mathrm{GABA}_{\mathrm{B}} \mathrm{R}$ (Fig. $3 D$ and supplemental Fig. $2 C$, available at www.jneurosci.org as supplemental material). Thus, GABAergic and glutamatergic modulation of calcium spikes is mediated largely by metabotropic receptors. Spikes are triggered by calcium-dependent action potentials that are terminated by activation of potassium channels. Accordingly, these results are consistent with a more depolarized resting potential that reduces the distance to threshold, enhancement of voltage-gated calcium channel activity, or postinhibition rebound excitation after potassium channel activation (Takeshita et al., 1996; Kim et al., 1997; Luthi et al., 1997; Linn and Gafka, 1999; Shen and Slaughter, 1999; Mathie, 2007). GABA $\mathrm{A}$ and AMPAR may contribute to spike incidence on the dorsal but not ventral surface because RBs are the only ones depolarized by GABA throughout development (Bixby and Spitzer, 1982) and dorsal interneurons express calcium-permeable AMPAR (Rohrbough and Spitzer, 1999).

The previous demonstration of activity-dependent transmitter specification by the frequency of calcium spiking (Borodinsky et al., 2004) was said to be homeostatic based on consideration of the effects of transmitters on ionotropic receptor activation. In contrast, the results reported here reveal that activation of
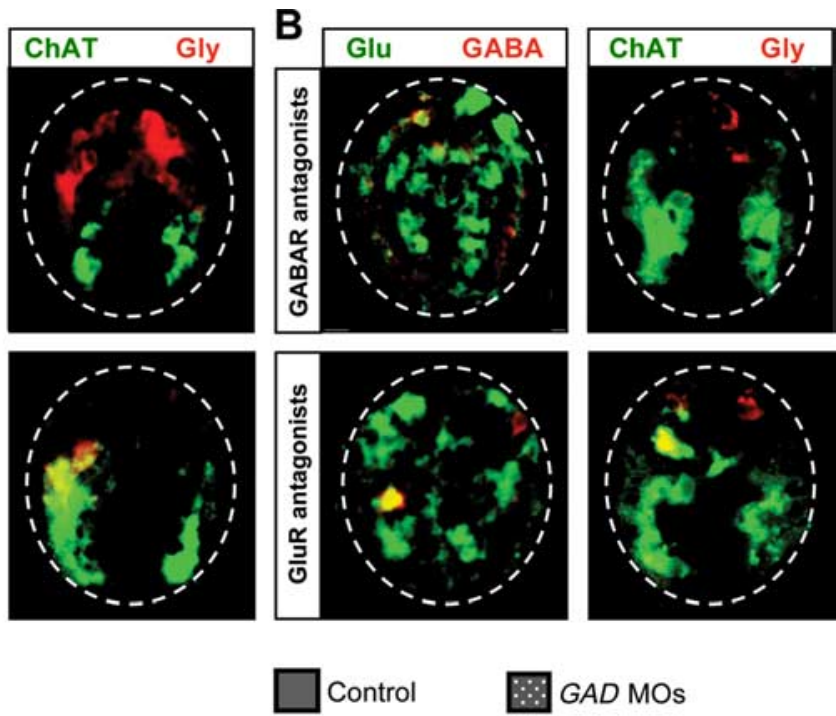

Control MO GABAR antagonists GluR antagonists

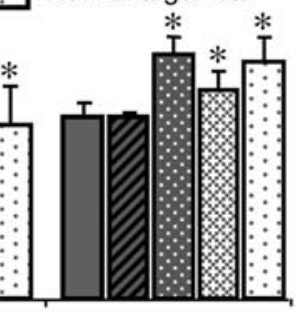

Glutamate

ChAT
Glycine

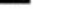

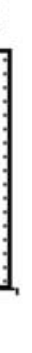

Figure 2. Blocking GABAergic or glutamatergic signaling changes neurotransmitter expression. $A$, Immunostaining for Glu/ GABA and ChAT/Gly in $3 \mathrm{~d}$ larvae (stage 41) developed from embryos injected with control morpholino (control MO) or GAD neurons expressing different transmitters at $3 \mathrm{~d}$ of development after suppression of GABAergic or glutamatergic signaling. $n \geq$ 5 embryos for each condition. Values are mean \pm SEM; asterisks indicate a significant difference from control.

metabotropic receptors regulates the incidence of calcium spiking that enables generation of different frequencies of spiking. Thus, embryonic GABA and glutamate appear to drive the activity that causes activity-dependent homeostatic transmitter specification.

Because GABA and glutamate generate calcium spikes mainly through activation of metabotropic receptors, we tested whether blockade of either $\mathrm{GABA}_{\mathrm{B}} \mathrm{R}$ or mGluRIII alone caused changes in transmitter expression similar to those observed with antagonist combinations (compare Fig. 2). Beads were loaded with phaclofen or MSOP and implanted at the time of neural tube closure; larvae were fixed at $3 \mathrm{~d}$ of age to examine transmitter expression. Indeed, when beads were implanted with either drug by itself, changes in neurotransmitter expression were similar to those after application of GABAR or GluR antagonist cocktails (Fig. 4). Blockade of either phaclofen or MSOP increases the number of neurons expressing excitatory transmitters and decreases the number of neurons expressing inhibitory transmitters, consistent with a homeostatic response to suppressed calcium spiking.

\section{$\mathrm{GABA}_{\mathrm{B}}$ and mGluRIII activate PKA and PKC}

To identify steps in signal transduction downstream of GAB$A_{B} R$ and mGluRIII, we imaged calcium spikes in the presence of antagonists of PKA or PKC, because these kinases are tar- 
A
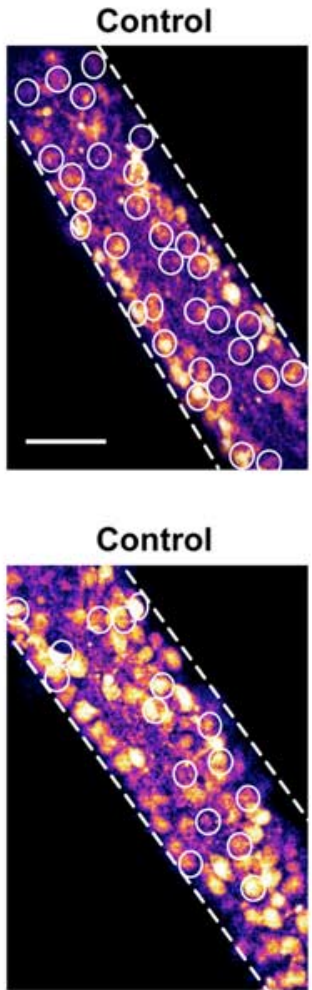

B

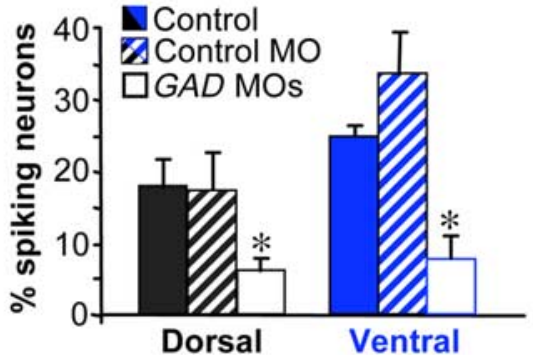

C
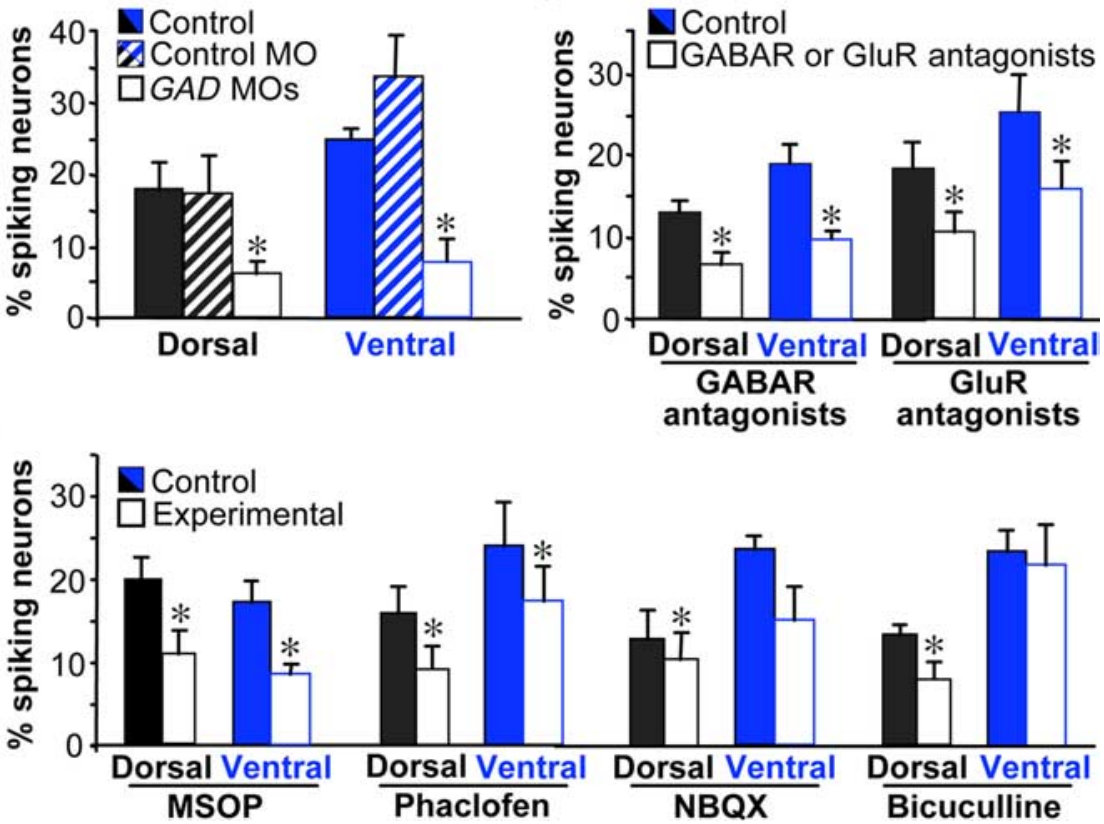

Figure 3. Blocking GABAergic or glutamatergic signaling decreases the incidence of calcium spike activity. $A$, Calcium spike incidence (white circles) on the ventral surface of the neural tube of control, control M0, and GAD65 plus GAD67 M0 (GAD MO)-injected embryos or in the presence of pooled GABAR or GluR antagonists. Scale bar, $50 \mu \mathrm{m}$. B, C, Spike incidence is reduced dorsally and ventrally in GAD65/67 M0-injected embryos and by pooled GABAR or GluR antagonists. D, Calcium spike incidence in the presence of single receptor antagonists. $n \geq 5$ stage $25-28$ embryos for each condition. Values are mean \pm SEM; asterisks indicate a significant difference from control.

gets of $\mathrm{GABA}_{\mathrm{B}} \mathrm{R}$ and mGluRIII (Olianas and Onali, 1999; Shen and Slaughter, 1999; Catsicas and Mobbs, 2001; Evans et al., 2001; Couve et al., 2002; Martin et al., 2004) and modulate the properties of calcium and potassium channels (Taylor et al., 2000; Park et al., 2003; Zhang et al., 2003; Hoogland and Saggau, 2004; Mathie, 2007). PKC and PKA could inhibit tandem pore domain potassium channels that set the membrane potential or engage lowvoltage- and high-voltage-activated calcium currents and potassium currents involved in generating calcium spikes in these neurons ( $\mathrm{Gu}$ and Spitzer, 1993). Blocking PKA with KT5720 decreases calcium spiking (Gorbunova and Spitzer, 2002); spike incidence is reduced on the dorsal surface, with no effect on spike generation on the ventral surface. Blocking PKC with bisindolylmaleimide reduces spike incidence both dorsally and ventrally (Fig. 5). No changes in spike frequency are detected (supplemental Fig. $2 D$, available at www.jneurosci.org as supplemental material). To determine whether the kinases are downstream of $\mathrm{GABA}_{\mathrm{B}}$ and mGluRIII, we tested whether stimulation with agonists of these kinases bypasses the effect of receptor antagonists and rescues calcium spiking. Indeed, decreases in spike incidence in the presence of either MSOP or phaclofen are prevented by N6-benzoyl-cAMP to activate PKA on the dorsal surface of the neural tube and by PMA to stimulate PKC on either the dorsal or ventral surface of the neural tube (Fig. 5). Although we do not know whether the actions of kinase antagonists and agonists are cell autonomous, these results suggest that PKA and PKC mediate the effects of activation of $\mathrm{GABA}_{\mathrm{B}} \mathrm{R}$ and mGluRIII on calcium spiking.

\section{Neurotransmitter specification occurs} during a restricted period

We tested the presence of a sensitive period for GABA- and Glu-mediated transmitter specification by implanting beads loaded with GABAR and GluR antagonists to suppress calcium spikes at different stages of development. Altering GABAergic and glutamatergic signaling leads to an increase in the numbers of neurons expressing glutamate and a decrease in the number of neurons expressing GABA during an interval of $\sim 15 \mathrm{~h}$ (Fig. 6). To correlate the sensitive period for GABA and glutamate regulation of transmitter expression with that of calcium spikes, we then determined the sensitive period for calcium spikedependent regulation of transmitter expression. We suppressed or enhanced spike activity by local delivery of voltagegated channel antagonists or veratridine, a sodium channel agonist (Borodinsky et al., 2004), and identified a similar interval for activity-dependent regulation of transmitter expression (Fig. 6 and supplemental Fig. 3, available at www.jneurosci.org as supplemental material). The stages during which calcium spikes are generated spontaneously are extended by application of TEA to 


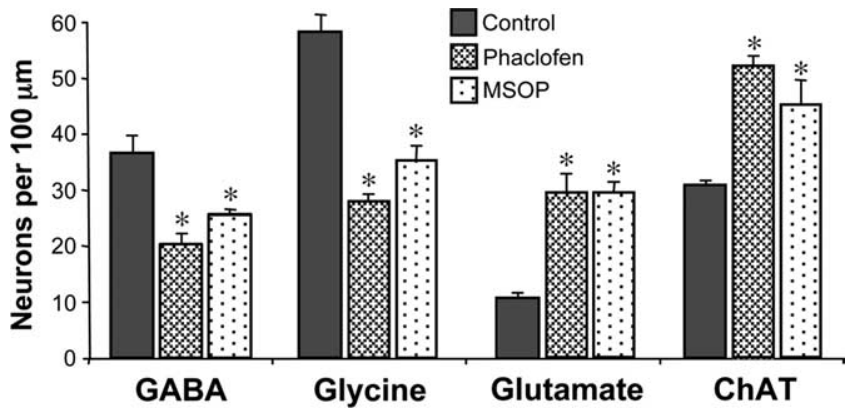

Figure 4. Blocking $G_{A B A_{B}}$ or $m G$ luRIII receptors changes neurotransmitter expression. Number of neurons expressing different transmitters at $3 \mathrm{~d}$ of development after suppression of $\mathrm{GABA}_{B}$ or mGluRIII signaling. Immunostaining was performed on $3 \mathrm{~d}$ larvae (stage 41) developed from embryos implanted with beads containing antagonists of $G_{A B A_{B}} R$ (phaclofen) or mGluRIII (MSOP). Control embryos were interleaved in parallel. $n \geq 4$ embryos for each condition. Values are mean $\pm S E M$; asterisks indicate a significant difference from control. stream mechanisms to generate the cell-type-specific frequencies of spikes reported previously (Borodinsky et al., 2004). The incidence of calcium spiking is permissive for spike frequency-dependent transmitter specification. Thus, when the incidence is reduced, spike frequency is zero in a population of neurons, leading to an increase in the incidence of expression of excitatory transmitters and a decrease in the incidence of expression of inhibitory transmitters.

We hypothesize that the activation of PKA and PKC leads to phosphorylation of ion channels that changes the amplitude of their current or shifts their conductance-voltage relationship. Likely candidates include tandem pore domain potassium channels (e.g., TASK [two-pore domain weak inwardly rectifying $\mathrm{K}^{+}$ channel (TWIK)-related acid-sensitive $\mathrm{K}^{+}$channel] or TREK [TWIK-related $\mathrm{K}^{+}$channel]) that regulate the resting potential, setting the distance from threshold and thereby the incidence of firing. The low-voltage-activated calcium channels and one or more classes of voltage-activated potassium channels are also candidates. The results of changes in channel properties could be to increase the excitability of the neurons and, thus, the incidence of calcium spikes. The frequency of firing would then depend on the constellations of ion channels expressed in different classes of neurons.

Blockade of GABA or glutamate receptors only suppresses spikes in half of the neurons on the dorsal and ventral surfaces of the neural tube, indicating that some cells generate spikes in response to GABA and glutamate whereas others do not. Interestingly, the effect on neurotransmitter expression of blocking spikes partially with $G A D$ MOs or with GABA receptor or glutamate receptor antagonists is similar to the result of suppressing spikes completely, suggesting that GABA and glutamate responsive neurons are the plastic population capable of altered transmitter expression. These findings raise two questions: first, what drives spike activity in the population of neurons that is not affected by block voltage-gated potassium channels, but local delivery of TEA plus veratridine does not increase the duration of the sensitive period (supplemental Fig. 3C-E, available at www.jneurosci.org as supplemental material). These results imply that GABA and glutamate regulate transmitter expression via calcium spikes during a restricted period, but that calcium spikes are not sufficient to do so on their own and require a specific developmental context (Fig. 7).

\section{Discussion}

The widespread embryonic expression of GABA and glutamate suggested that these neurotransmitters could have significant functions (Lauder et al., 1986; Ma et al., 1992; Antal et al., 1994; Berki et al., 1995). Our findings demonstrate that GABA and glutamate signaling drive the generation of calcium spikes that in turn specify transmitter expression. These actions are mediated largely by metabotropic receptors that activate several kinases, as indicated by the actions of pharmacological antagonists suppressing spike generation in imaging experiments. Interestingly, this signaling regulates the incidence, but not the frequency, of calcium spikes. GABA and glutamate appear to open an activity gate that allows down-
GABA or glutamate receptor antagonists? Amine and peptide neurotransmitters are also expressed at early stages of development (Lauder et al., 1981; Hu et al., 2001; McLean and Fetcho, 2004) and are candidates to evaluate. Second, what is the function of calcium spike activity in these neurons if it does not regulate the expression of GABA, glutamate, glycine or acetylcholine? On the one hand, spike activity may regulate expression of peptide and amine transmitters, following the paradigm we report here. Alternatively, spike activity may regulate other aspects of neuronal differentiation, such as axon extension or ion channel expression.

Our results show that metabotropic receptors activate PKA and $\mathrm{PKC}$ signaling pathways in the embryonic Xenopus spinal cord, which stimulate generation of calcium spikes. These results stand in contrast with observations in the mature nervous system, reporting activation of potassium currents and suppression of calcium currents by $\mathrm{GABA}_{\mathrm{B}}$ and mGluR receptors (Isaacson, 1998; Nicoll, 2004; Giustizieri et al., 2005). One possibility is that the G-proteins are coupled to excitatory machinery at early stages of development and to inhibitory components in the mature ner- 
A

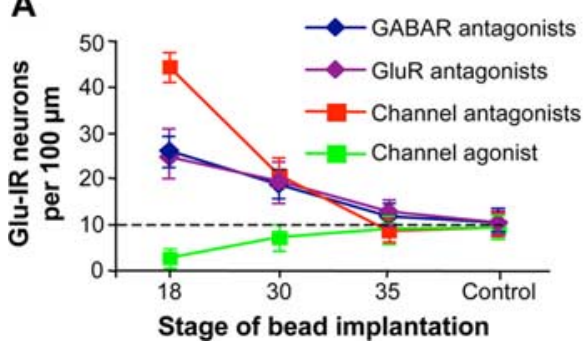

B

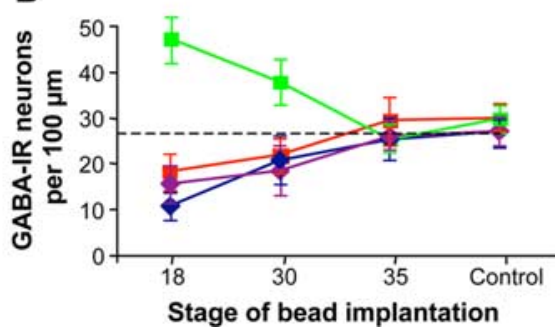

Figure 6. GABA- and glutamate-driven activity-dependent transmitter expression is restricted to a sensitive period. Beads containing agents to block GluR or GABAR (as in Fig. 2) or to suppress or enhance voltage-gated channel activity (Borodinsky et al., 2004) were implanted at various developmental times and larvae were fixed and transmitter expression scored at $3 \mathrm{~d}$ of development [stage (St) 41]. Similar results were obtained after fixation of embryos at a constant interval of $2 \mathrm{~d}$ after bead implantation (data not shown). $A$, GluR and GABAR antagonists increase the number of Glu-immunoreactive neurons during a period of $\sim 15 \mathrm{~h}$ from St 18 to St 30; suppressing or enhancing voltage-gated channel activity increases and decreases the numbers of Glu-immunoreactive neurons during the same period. $\boldsymbol{B}$, GluR and GABAR antagonists decrease the number of GABAimmunoreactive neurons during this period; suppressing or enhancing voltage-gated channel activity decreases and increases the numbers of GABA-immunoreactive neurons. Dashed lines indicate control values. Transmitter expression after bead implantation at $\mathrm{St} 18$ or 30 is significantly different from control. Changes in transmitter expression after bead implants at $\mathrm{St} 30$ or 35 are significantly smaller than those obtained when beads are implanted at St 18, except for GluR beads at St 30. $n \geq 5$ embryos for each condition. Values are mean \pm SEM and are connected by lines according to the type of bead implanted.

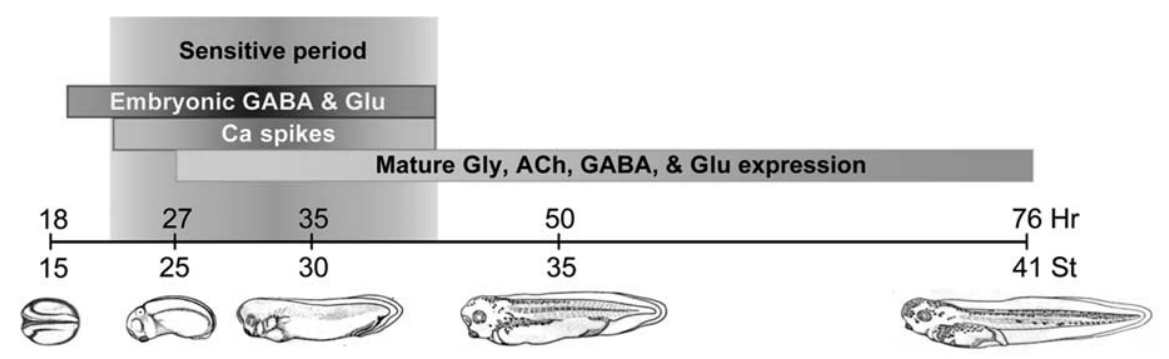

Figure 7. Model for GABA/glutamate-activated Ca spike-mediated transmitter specification. GABA and glutamate are promiscuously expressed early in development. During a sensitive period, these transmitters activate receptors to trigger Ca spikes that specify transmitter expression at later stages.

vous system. Evolution is likely to have been opportunistic in mixing and matching receptors with ion channels for specific contexts in particular classes of neurons. Consistent with this view, dorsal neurons also make use of $\mathrm{GABA}_{\mathrm{A}}$ and AMPA receptors as well as PKA signaling to generate spikes, whereas ventral neurons do not. These findings indicate that different populations of neurons have distinct repertoires of signaling pathways responsible for producing activity.

We identify a sensitive period in vivo during which transmitter expression is altered by modulating activity. Perturbation of activity at later times is ineffective, identifying its importance during this time window. Whether changes in transmitter specification achieved in this way can be reversed is still unknown; thus, we do not know if it is a critical period as well. This period is different from most of the others described in development of the nervous system (Hensch, 2004; Knudsen, 2004) in that it precedes synapse formation. Paracrine stimulation by GABA and glutamate presumably joins with intracellular signaling by kinases, transcription factors, and other components to enable transmitter plasticity; changes in the expression of this machinery close the window of opportunity. It will be useful to analyze activity-dependent gene expression during this sensitive period. An understanding of the molecular mechanisms involved in activity-dependent transmitter specification may have therapeutic implications for treating disorders of transmitter metabolism in the mature nervous system.

Spontaneous electrical activity is a transient feature of many developing nervous systems (Spitzer, 2006) but its functions have been obscure in many cases. Our results suggest a model in which neurotransmitters synthesized and released early in the development of the nervous system trigger electrical activity that drives neuronal differentiation. This activity likely engages a cell-type-specific repertoire of signaling and effector molecules. Such an arrangement may be expected to enable environmental stimuli that alter spontaneous activity to influence early stages of neuronal development. The combination would provide a level of plasticity promoting appropriate and robust context-dependent maturation of the nervous system. It will be interesting to identify the environmental stimuli capable of altering transmitter specification before synaptogenesis.

\section{References}

Antal M, Berki AC, Horvath L, O’Donovan MJ (1994) Developmental changes in the distribution of gamma-aminobutyric acidimmunoreactive neurons in the embryonic chick lumbosacral spinal cord. J Comp Neurol 343:228-236.

Ben-Ari Y, Gaiarsa JL, Tyzio R, Khazipov R (2007) GABA: a pioneer transmitter that excites immature neurons and generates primitive oscillations. Physiol Rev 87:1215-1284.

Berki AC, O’Donovan MJ, Antal M (1995) Developmental expression of glycine immunoreactivity and its colocalization with GABA in the embryonic chick lumbosacral spinal cord. J Comp Neurol 362:583-596.

Bixby JL, Spitzer NC (1982) The appearance and development of chemosensitivity in RohonBeard neurones of the Xenopus spinal cord. J Physiol (Lond) 330:513-536. Blanton MG, Lo Turco JJ, Kriegstein AR (1990) Endogenous neurotransmitter activates $\mathrm{N}$-methyl-D-aspartate receptors on differentiating neurons in embryonic cortex. Proc Natl Acad Sci USA 87:8027-8030.

Bolteus AJ, Bordey A (2004) GABA release and uptake regulate neuronal precursor migration in the postnatal subventricular zone. J Neurosci 24:7623-7631.

Borodinsky LN, Root CM, Cronin JA, Sann SB, Gu X, Spitzer NC (2004) Activity-dependent homeostatic specification of transmitter expression in embryonic neurons. Nature 429:523-530.

Catsicas M, Mobbs P (2001) $\mathrm{GABA}_{\mathrm{B}}$ receptors regulate chick retinal calcium waves. J Neurosci 21:897-910.

Couve A, Thomas P, Calver AR, Hirst WD, Pangalos MN, Walsh FS, Smart TG, Moss SJ (2002) Cyclic AMP-dependent protein kinase phosphorylation facilitates $\mathrm{GABA}_{\mathrm{B}}$ receptor-effector coupling. Nat Neurosci 5:415-424.

Deng L, Yao J, Fang C, Dong N, Luscher B, Chen G (2007) Sequential postsynaptic maturation governs the temporal order of GABAergic and glutamatergic synaptogenesis in rat embryonic cultures. J Neurosci 27:10860-10869.

Evans DI, Jones RS, Woodhall G (2001) Differential actions of PKA and PKC in the regulation of glutamate release by group III mGluRs in the entorhinal cortex. J Neurophysiol 85:571-579.

Flint AC, Dammerman RS, Kriegstein AR (1999) Endogenous activation of metabotropic glutamate receptors in neocortical development causes neuronal calcium oscillations. Proc Natl Acad Sci USA 96:12144-12149.

Giustizieri M, Bernardi G, Mercuri NB, Berretta N (2005) Distinct mechanisms of presynaptic inhibition at GABAergic synapses of the rat substantia nigra pars compacta. J Neurophysiol 94:1992-2003. 
Gorbunova YV, Spitzer NC (2002) Dynamic interactions of cyclic AMP transients and spontaneous $\mathrm{Ca}^{2+}$ spikes. Nature 418:93-96.

Gu X, Spitzer NC (1993) Low-threshold $\mathrm{Ca}^{2+}$ current and its role in spontaneous elevations of intracellular $\mathrm{Ca}^{2+}$ in developing Xenopus neurons. J Neurosci 13:4936-4948.

Hensch TK (2004) Critical period regulation. Annu Rev Neurosci 27:549-579.

Hensey C, Gautier J (1998) Programmed cell death during Xenopus development: a spatio-temporal analysis. Dev Biol 203:36-48.

Hoogland TM, Saggau P (2004) Facilitation of L-type $\mathrm{Ca}^{2+}$ channels in dendritic spines by activation of beta 2 adrenergic receptors. J Neurosci 24:8416-8427.

Hu Z, Rodriguez WI, Tam J, Cheng JW, Cohen-Cory S, Waschek JA (2001) Embryonic expression of pituitary adenylyl cyclase-activating polypeptide and its selective type I receptor gene in the frog Xenopus laevis neural tube. J Comp Neurol 441:266-275.

Isaacson JS (1998) $\mathrm{GABA}_{\mathrm{B}}$ receptor-mediated modulation of presynaptic currents and excitatory transmission at a fast central synapse. J Neurophysiol 80:1571-1576.

Kim U, Sanchez-Vives MV, McCormick DA (1997) Functional dynamics of GABAergic inhibition in the thalamus. Science 278:130-134.

Knudsen EI (2004) Sensitive periods in the development of the brain and behavior. J Cogn Neurosci 16:1412-1425.

Komuro H, Rakic P (1996) Intracellular $\mathrm{Ca}^{2+}$ fluctuations modulate the rate of neuronal migration. Neuron 17:275-285.

Lauder JM, Wallace JA, Krebs H (1981) Roles for serotonin in neuroembryogenesis. Adv Exp Med Biol 133:477-506.

Lauder JM, Han VK, Henderson P, Verdoorn T, Towle AC (1986) Prenatal ontogeny of the GABAergic system in the rat brain: an immunocytochemical study. J Neurosci 19:465-493.

Linn CL, Gafka AC (1999) Activation of metabotropic glutamate receptors modulates the voltage-gated sustained calcium current in a teleost horizontal cell. J Neurophysiol 81:425-434.

Liu X, Wang Q, Haydar TF, Bordey A (2005) Nonsynaptic GABA signaling in postnatal subventricular zone controls proliferation of GFAPexpressing progenitors. Nature Neurosci 8:1179-1187.

Lopez JM, Smeets WJ, Gonzalez A (2002) Choline acetyltransferase immunoreactivity in the developing brain of Xenopus laevis. J Comp Neurol 453:418-434.

LoTurco JJ, Owens DF, Heath MJ, Davis MB, Kriegstein AR (1995) GABA and glutamate depolarize cortical progenitor cells and inhibit DNA synthesis. Neuron 15:1287-1298.

Luthi A, Gahwiler BH, Gerber U (1997) 1S, 3R-ACPD induces a region of negative slope conductance in the steady-state current-voltage relationship of hippocampal pyramidal cells. J Neurophysiol 77:221-228.

Ma W, Behar T, Barker JL (1992) Transient expression of GABA immunoreactivity in the developing rat spinal cord. J Comp Neurol 325:271-290.

Martin SC, Steiger JL, Gravielle MC, Lyons HR, Russek SJ, Farb DH (2004) Differential expression of gamma-aminobutyric acid type B receptor sub- unit mRNAs in the developing nervous system and receptor coupling to adenylyl cyclase in embryonic neurons. J Comp Neurol 473:16-29.

Mathie A (2007) Neuronal two-pore-domain potassium channels and their regulation by G protein-coupled receptors. J Physiol (Lond) 578:377-385.

McDearmid JR, Liao M, Drapeau P (2006) Glycine receptors regulate interneuron differentiation during spinal network development. Proc Natl Acad Sci USA 103:9679-9684.

McLean DL, Fetcho JR (2004) Ontogeny and innervation patterns of dopaminergic, noradrenergic, and serotonergic neurons in larval zebrafish. J Comp Neurol 480:38-56.

Nicoll RA (2004) My close encounter with $\mathrm{GABA}_{\mathrm{B}}$ receptors. Biochem Pharmacol 68:1667-1674.

Nordlander RH (1993) Cellular and subcellular distribution of HNK-1 immunoreactivity in the neural tube of Xenopus. J Comp Neurol 335:538-551.

Olianas MC, Onali P (1999) $\mathrm{GABA}_{\mathrm{B}}$ receptor-mediated stimulation of adenylyl cyclase activity in membranes of rat olfactory bulb. Br J Pharmacol 126:657-664.

Park JY, Jeong SW, Perez-Reyes E, Lee JH (2003) Modulation of $\mathrm{Ca}_{\mathrm{v}} 3.2$ T-type $\mathrm{Ca}^{2+}$ channels by protein kinase C. FEBS Lett 547:37-42.

Roberts A, Dale N, Ottersen OP, Storm-Mathisen J (1988) Development and characterization of commissural interneurones in the spinal cord of Xenopus laevis embryos revealed by antibodies to glycine. Development 103:447-461.

Rohrbough JC, Spitzer NC (1999) $\mathrm{Ca}^{2+}$-permeable AMPA receptors and spontaneous presynaptic transmitter release at developing excitatory spinal synapses. J Neurosci 19:8528-8541.

Schlosser G, Koyano-Nakagawa N, Kintner C (2002) Thyroid hormone promotes neurogenesis in the Xenopus spinal cord. Dev Dyn 225:485-498.

Shen W, Slaughter MM (1999) Metabotropic GABA receptors facilitate L-type and inhibit $\mathrm{N}$-type calcium channels in single salamander retinal neurons. J Physiol (Lond) 516:711-718.

Spitzer NC (2006) Electrical activity in early neuronal development. Nature 444:707-712.

Taira M, Hayes WP, Otani H, Dawid IB (1993) Expression of LIM class homeobox gene Xlim-3 in Xenopus development is limited to neural and neuroendocrine tissues. Dev Biol 159:245-256.

Takeshita Y, Harata N, Akaike N (1996) Suppression of $\mathrm{K}^{+}$conductance by metabotropic glutamate receptor in acutely dissociated large cholinergic neurons of rat caudate putamen. J Neurophysiol 76:1545-1558.

Taylor SC, Green KN, Carpenter E, Peers C (2000) Protein kinase C evokes quantal catecholamine release from PC12 cells via activation of L-type $\mathrm{Ca}^{2+}$ channels. J Biol Chem 275:26786-26791.

Yacubova E, Komuro H (2002) Stage-specific control of neuronal migration by somatostatin. Nature $415: 77-81$.

Zhang M, Fearon IM, Zhong H, Nurse CA (2003) Presynaptic modulation of rat arterial chemoreceptor function by 5 -HT: role of $\mathrm{K}^{+}$channel inhibition via protein kinase C. J Physiol (Lond) 551:825-842. 